\title{
Analisis Pengaruh Temperatur dan Kebisingan Terhadap Kerja Sistem Cardiovascular di CV. Bintang Terang Medan
}

\author{
Rini Halila Nasution \\ Program Studi Teknik Industri, Universitas Harapan \\ Jl. HM. Joni 70 Medan 20218, Indonesia \\ email: rinihalilanst@gmail.com
}

\begin{abstract}
Increased employee productivity is very important in an organization. Increased employee productivity can be affected by the physical work environment and non-physical work environment. Physical work environment can be classified as, lighting level, noise level and temperature of work environment, while non-physical work environment factors can be classified from the relationship between superiors and subordinates, and the relationship between employees. The results of this study show that normal working room temperature levels $\left(24-28^{\circ} \mathrm{C}\right)$ and above normal threshold $\left(29-34^{\circ} \mathrm{C}\right)$ and normal workplace noise level (80-84dB) and above threshold (85-88dB) have an effect on cardivascular health which can lead to decreased employee performance. From the results of data processing Kolmogorov-Smirnov Test, Ho accepted because DHit $<D(1,63>3,59)$. This means that data is normally distributed. The analysis results obtained by each factor of noise and temperature significantly influence the frequency of the operator's heartbeat, while the interaction of temperature and noise does not significantly affect the operator's heart rate.
\end{abstract}

Keywords: Cardiovascular, Noise, Temperaturesection.

\begin{abstract}
Abstrak
Peningkatan produktivitas karyawan sangat penting dalam suatu organisasi. Peningkatan produktivitas karyawan dapat dipengaruhi oleh lingkungan kerja fisik dan lingkungan kerja non-fisik. Lingkungan kerja fisik dapat diklasifikasikan sebagai, tingkat pencahayaan, tingkat kebisingan dan suhu lingkungan kerja, sedangkan non-fisik faktor lingkungan kerja dapat diklasifikasikan dari hubungan antara atasan dan bawahan, dan hubungan antara karyawan. Hasil kajian penelitian ini menunjukkan bahwa tingkat suhu ruang kerja normal $\left(24-28{ }^{\circ} \mathrm{C}\right)$, tingkat suhu diatas nilai ambang batas $\left(29-34^{\circ} \mathrm{C}\right)$ lalu tingkat kebisingan di tempat kerja normal (80-84db) dan diatas nilai ambang batas kebisingan (85-88dB) berpengaruh pada kesehatan cardiovascular yang bisa mengakibatkan kinerja karyawan menurun. Dari hasil pengolahan data Uji Kolmogorov-Smirnov, Ho diterima karena $D_{H i t}<D \alpha(1,63>3,59)$. Ini artinya data berdistribusi normal. Hasil analisis didapat masing-masing faktor yakni kebisingan dan temperatur berpengaruh secara signifikan terhadap frekuensi denyut jantung operator, sedangkan Interaksi temperature dan kebisingan tidak berpengaruh secara signifikan terhadap frekuensi denyut jantung operator.
\end{abstract}

Kata kunci: Cardiovascular, Kebisingan, Temperatur

\section{Pendahuluan}

Perkembangan industry di Indonesia tidak hanya membawa dampak positif bagi pertumbuhan perekonomian bangsa Indonesia, namun di sisi lain juga menimbulkan dampak negatif dengan meningkatnya potens bahaya dan penyakit akibat kerja. Potensi bahaya biasanya bersumber dari lingkungan kerja (fisik, kimia, biologi), bangunan dan instalasi gedung, bahan dan proses produksi, dan lain-lain. Sumbersumber bahaya tersebut jika tidak dikendalikan secara optimal dapat mengakibatkan kecelakaan dan penyakit akibat kerja. Oleh karena itu, seiring dengan perkembangan teknologi industri maka harus disertai dengan peningkatan keselamatan dan kesehatan tenaga kerja. 
Keselamatandan kesehatan kerja merupakan hal yang paling penting dalam pengelolaan perusahaan karena tenaga kerja adalah manusia yang memiliki hak asasi untuk hidup dengan sehat dan selamat. Selain itu pemerintah juga sudah mengeluarkan Peraturan Menteri Tenaga kerja No.5 Tahun 1996 tentang Sistem Manajemen Keselamatan dan Kesehatan Kerja yang berisi tentang kewajiban perusahaan yang mempekerjakan tenaga kerja lebih dari seratus orang dan mengandung potensi bahaya yang dapat mengakibatkan kecelakaan kerja dan penyakit akibat kerja untuk memiliki komitmen terhadap keselamatan dan kesehatan kerja serta menerapkan system manajemen keselamatan dan kesehatan kerja.

Berdasarkan data International Labor Organization pada tahun 1999, penyakit cardiovascular berada diperingkat ke empat sebagai penyakit akibat kerja yang paling sering terjadi. Data tersebut diramalkan akan semakin meningkat seiring dengan perkembangan teknologi permesinan. Penyakit tersebut diakibatkan tidak berfungsinya sistem cardiovascular yang terdiri dari jantung, darah dan pembuluh darah. Sistem cardiovascular berfungsi sebagai sistem sirkulasi nutrisi makanan, oksigen, karbondioksida, system kekebalan tubuh dan racun. Jantung bekerja memompa darah untuk mendistribusikan zat-zat yang penting bagi tubuh melalui pembuluh darah. Jika jantung tidak bekerja secara optimal, maka dapat diindikasikan terjadi ketidakseimbangan fungsi tubuh. Pada penelitian ini, nilai output system cardiovascular yang akan diteliti adalah besarnya nilai frekuensi denyut jantung.

Keadaan lingkungan fisik di CV. Bintang Terang Medan dalam memproduksi Panci yang berbahan campuran aluminium dan besi dapat dikategorikan sebagai kondisi yang tidak ergonomis. Tingkat kebisingan lantai produksi lebih dari $85 \mathrm{~dB}$ atau berada di atas Nilai Ambang Batas Kebisingan berdasarkan Keputusan Menteri Tenaga Kerja No. Kep. 51/MEN/1999 untuk batas waktu kerja terusmenerus tidak lebih dan 8 jam per hari atau 40 jam seminggu. Sumber kebisingan berasal dari mesin-mesin produksi yang berjumlah 8-9 buah mesin di line produksi. Mesin-mesin yang digunakan dalam proses produksi pembuatan panci mengakibatkan tempat produksi menjadi panas, dengan temperatur hingga mencapai $35^{\circ} \mathrm{C}$. Pada kondisi lingkungan yang ergonomis, temperatur lingkungan kerja sebesar $24^{\circ} \mathrm{C}-$ $26^{\circ} \mathrm{C}$ (Wignjosoebroto,1995) serta pencahaan yang kurang baik. Bekerja di lingkungan yang panas dengan ventilasi yang kurang baik serta pada tingkat kebisingan yang tinggi, suhu ruangan dan pencahaan yang lebih dari batas standart dapat menjadi akar masalah kesehatan operator produksi.

Adapun tujuan dari penelitian ini, yakni :

1. Untuk mengetahui pengaruh tingkat kebisingan, temperature dan pencahayaan lingkungan terhadap kerja sistem cardiovascular operator produksi.

2. Untuk menganalisa seberapa besar pengaruh tingkat kebisingan, temperature dan pencahayaan lingkungan terhadap kerja sistem cardiovascular operator produksi.

\section{Methodologi}

Metodologi penelitian yang digunakan adalah penelitian deskriptif, karena penelitian deskriptif tidak dimaksudkan untuk menguji hipotesis tertentu. Tetapi hanya menggambarkan apa adanya tentang suatu variabel, gejala atau keadaan. Memang adakalanya dalam penelitian ingin juga membuktikan dugaan, tetapi tidak terlalu lazim.

Penelitian ini menggunakan penelitian deskriptif jenis studi kasus, yang mana pengertian dari studi kasus adalah suatu strategi melakukan penelitian dengan gejala permasalahan yang ada bahkan yang sudah terjadi ,karena penulis mencoba mencermati sebuah unit secara mendalam. Penulis ingin mencoba menemukan semua variable penting yang melatarbelakangi timbulnya serta pengembangan variable tersebut Data yang dikumpulkan akan menjadi input pada tahap pengolahan data. Pada pengumpulan data penelitian ini menggunakan dua jenis data, yaitu data primer dan data sekunder.

Data yang akan diambil dalam penelitian ini adalah data primer dan data sekunder. Data primer yaitu data yang diperoleh dari pengamatan dan penelitian secara langsung di lapangan. Data primer yang digunakan adalah data aktivitas karyawan dalam kegiatan produksi yang diperoleh dari pengukuran dan pengamatan langsung ke lantai produksi dan melakukan wawancara kepada operator. Data sekunder adalah data yang diambil dari berkas-berkas perusahaan. Dalam penelitian ini data sekunder diperoleh berdasarkan observasi dan dokumentasi perusahaan yang digunakan adalah alur informasi, jumlah produk yang dihasilkan perhari serta target pencapain perharinya. 
Seluruh kegiatan operator diamati dengan memberikan lingkungan kerja fisik dengan mengukur tingkat kebisingan, tingkat pencahayaan dan suhu ruang area produksi dan menghitung denyut nadi operator yang dihasilkan selama 8 jam kerja.

Metode pengolahan data adalah dengan melakukan uji kenormalan data dengan menggunakan uji Chi-Square dan perhitungan ANAVA Faktorial untuk pengujian hipotesis. Adapun flowchart metodologi penelitian seperti gambar dibawah ini.

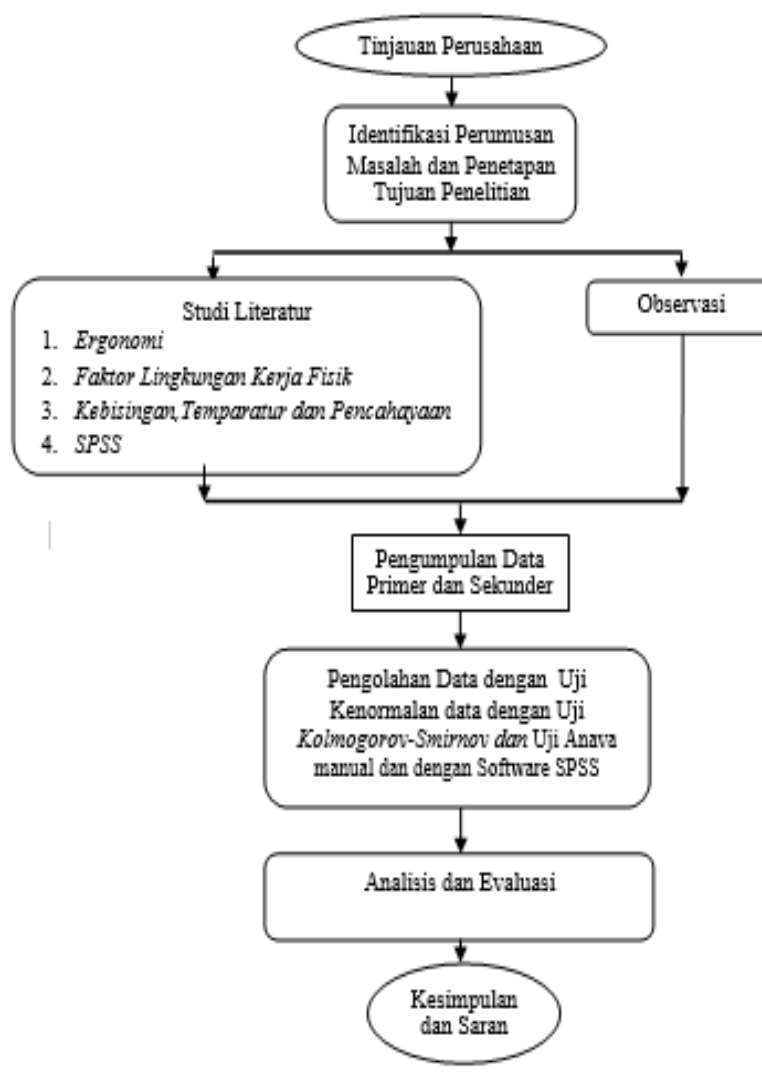

Gambar 1. Flowchart Metodologi Penilitian

\section{Analisa dan Pembahasan}

\subsection{Persiapan Eksperimen}

Pada penelitian ini tipe eksperimen yang dilakukan bukan merupakan eksperimen murni, tetapi termasuk ke dalam jenis ex-post facto. Hal tersebut dikarenakan faktor yang diteliti telah ada dan eksperimenter hanya mengukur efek dari faktor tersebut. Pada tahap persiapan, langkah pertama yang harus dilakukan adalah menentukan karakteristik eksperimen yang ditampilkan pada tabel 1 .
Tabel 1.

Karakteristik Eksperimen

\begin{tabular}{|c|c|}
\hline Karakteristik & Keterangan \\
\hline Unit eksperimen & Operator produksi \\
\hline \multirow{3}{*}{ Faktor } & a. Temperatur (A) \\
\hline & b. Kebisingan (B) \\
\hline & c. Pencahayaan (C) \\
\hline \multirow{4}{*}{ Level } & - $\quad \mathrm{A} 1\left(24-28^{\circ} \mathrm{C}\right)$ \\
\hline & - $\mathrm{A} 2\left(29-34^{\circ} \mathrm{C}\right)$ \\
\hline & - $\quad \mathrm{B} 1\left(80-84^{\circ} \mathrm{C}\right)$ \\
\hline & - $\quad \mathrm{B} 2\left(85-88^{\circ} \mathrm{C}\right)$ \\
\hline Variabel Respon & $\begin{array}{l}\text { Frekuensi denyut jantung } \\
\text { (denyut per menit) }\end{array}$ \\
\hline Randomisasi & $\begin{array}{l}\text { Randomisasi unit eksperimen } \\
\text { (operator produksi) }\end{array}$ \\
\hline & - $\quad$ A1_B1 \\
\hline Perlakuan & - $\quad$ A1_B2 \\
\hline тепакиап & - $\quad$ A2_B1 \\
\hline & - $\quad \mathrm{A} 2 \_\mathrm{B} 2$ \\
\hline Replikasi & $\begin{array}{l}11 \text { unit eksperimen per } \\
\text { perlakuan }\end{array}$ \\
\hline Metode eksperimen & Ekperimen faktorial \\
\hline
\end{tabular}

Prosedur pengukuran merupakan langkahlangkah sistematis yang dilakukan selama penelitian. Prosedur penelitian meliputi peralatan yang digunakan dan pelaksanaan penelitian. Pada penelitian ini dilakukan pengukuran tingkat temperatur, kebisingan, pencahayaan dan frekuensi denyut jantung operator.

Tabel 2.

Hasil Pengukuran Temperatur

\begin{tabular}{|c|c|c|c|c|c|c|c|c|c|c|c|c|}
\hline \multirow[b]{2}{*}{ Waktu Pengukuran } & \multicolumn{11}{|c|}{ Replikasi } & \multirow[b]{2}{*}{$\begin{array}{l}\text { Rata- } \\
\text { rata }\end{array}$} \\
\hline & $\begin{array}{c}\text { Titik1 } \\
\left({ }^{\circ} \mathrm{C}\right)\end{array}$ & $\begin{array}{c}\text { Titik2 } \\
\left({ }^{\circ} \mathrm{C}\right)\end{array}$ & $\begin{array}{c}\text { Titik } 3 \\
\left({ }^{2} \mathrm{C}\right)\end{array}$ & $\begin{array}{c}\text { Titik } 4 \\
\left({ }^{\circ} \mathrm{C}\right)\end{array}$ & $\begin{array}{c}\text { Titk } 5 \\
\left({ }^{\circ} \mathrm{C}\right)\end{array}$ & $\begin{array}{l}\text { Titik } 6 \\
\left({ }^{\circ} \mathrm{C}\right)\end{array}$ & $\begin{array}{c}\text { Titik } 7 \\
\left({ }^{\circ} \mathrm{C}\right)\end{array}$ & $\begin{array}{c}\text { Titik } 8 \\
\left({ }^{\circ} \mathrm{C}\right)\end{array}$ & $\begin{array}{c}\text { Titik } 9 \\
\left({ }^{\circ} C\right)\end{array}$ & $\begin{array}{c}\text { Titik } 10 \\
\left({ }^{\circ} \mathrm{C}\right)\end{array}$ & $\begin{array}{c}\text { Titik } 11 \\
\left({ }^{\circ} \mathrm{C}\right)\end{array}$ & \\
\hline Pagi 09:00 Wib & 26,7 & 26,8 & 26,8 & 26,6 & 25,9 & 25,9 & 25,6 & 25,7 & 26,2 & 25,7 & 25,2 & 26,1 \\
\hline Siang 11:00 Wib & 32,6 & 33,2 & 32,7 & 32,8 & 31,9 & 31,8 & 32 & 30,8 & 30,9 & 30,4 & 30,6 & 31,8 \\
\hline Siang 13:30 Wib & 33,6 & 33,8 & 33,3 & 33,7 & 32,9 & 32,8 & 32,1 & 31,5 & 31,7 & 30,8 & 30,2 & 32,4 \\
\hline Sore 15:30 Wib & 27,7 & 27,9 & 27,1 & 27,5 & 27 & 27,8 & 27,3 & 26,8 & 26,4 & 26,8 & 26 & 27,1 \\
\hline
\end{tabular}

Tabel 3.

Hasil Pengukuran Tingkat Kebisingan

\begin{tabular}{|c|c|c|c|c|c|c|c|c|c|c|c|c|}
\hline \multirow[b]{2}{*}{ Waktu Pengukuran } & \multicolumn{11}{|c|}{ Replikasi } & \multirow[b]{2}{*}{$\begin{array}{l}\text { Rata- } \\
\text { rata }\end{array}$} \\
\hline & $\begin{array}{c}\text { Titik1 } \\
\text { (dB) }\end{array}$ & $\begin{array}{l}\text { Titik2 } \\
(\mathrm{dB})\end{array}$ & $\begin{array}{l}\text { Titik3 } \\
\text { (dB) }\end{array}$ & $\begin{array}{c}\text { Titik } 4 \\
(\mathrm{~dB})\end{array}$ & $\begin{array}{c}\text { Titik } 5 \\
\text { (dB) }\end{array}$ & $\begin{array}{c}\text { Titik1 } \\
\text { (dB) }\end{array}$ & $\begin{array}{r}\text { Titik } 7 \\
(\mathrm{~dB})\end{array}$ & $\begin{array}{c}\text { Titik } 8 \\
\text { (dB) }\end{array}$ & $\begin{array}{l}\text { Titik9 } \\
\text { (dB) }\end{array}$ & $\begin{array}{c}\text { Titik } 10 \\
(\mathrm{~dB})\end{array}$ & $\begin{array}{c}\text { Titik } 11 \\
(\mathrm{~dB})\end{array}$ & \\
\hline Pagi09:00 Wib & 81,8 & 81,6 & 82,2 & 82,3 & 82,8 & 82,8 & 82,6 & 82,8 & 82,3 & 82,8 & 82,5 & 82,4 \\
\hline Slang 11:00 Wib & 83,8 & 83,9 & 83,8 & 83,6 & 83,8 & 83,8 & 83,7 & 83,8 & 83,9 & 83,4 & 83,1 & 83,7 \\
\hline Siang $13: 30 \mathrm{Wib}$ & 86,1 & 85,6 & 87,4 & 85,2 & 87,3 & 87,9 & 87,6 & 87,4 & 87,2 & 87,3 & 86,1 & 86,8 \\
\hline Sore 15:30 Wib & 86,6 & 85,8 & 87,7 & 87,2 & 86,8 & 86,8 & 86,3 & 86,7 & 86,2 & 86,4 & 86,2 & 86,6 \\
\hline
\end{tabular}


Tabel 4.

Data Hasil Pengukuran Frekuensi Denyut Jantung (denyut per menit)

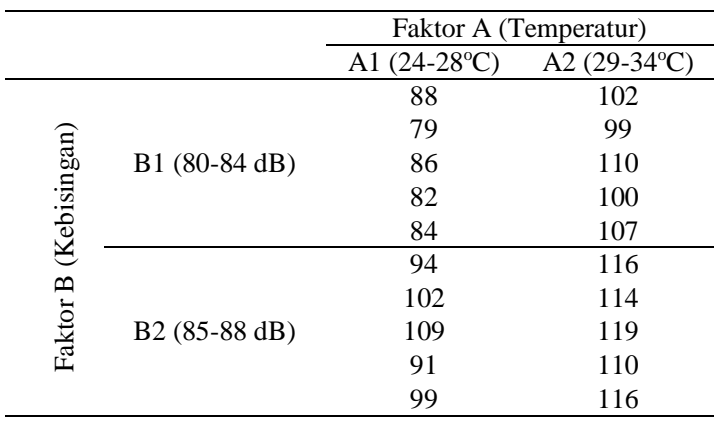

\subsection{Uji Kenormalan Data dengan Uji}

\section{Kolmogorov-Smirnov}

Uji Kolmogorov-Smirnov digunakan untuk menetahui apakah distribusi nilai-nilai sampel yang teramati sesuai dengan distribusi teoritis. Uji Kolmogorov-Smirnov beranggapan bahwa distribusi variabel yang sedang diuji bersifat kontinu dan pengambilan sampel secara acak sederhana. Dengan demikian uji ini dapat digunakan bila variabel diukur paling sedikit dalam skala ordinal. Uji keselarasan Kolmogorov-Smirnov dapat diterapkan pada dua keadaan:

1. Menguji apakah suatu sampel mengikuti suatu bentuk distribusi populasi teoritis.

2. Menguji apakah dua buah sampel berasal dari dua populasi yang identik.

Dihitung selisih antara $\mathrm{Fa}(\mathrm{X})$ dengan $\mathrm{Fe}(\mathrm{X})$. Diambil selisih maksimum dan notasikan dengan D,

$$
\mathrm{D}=\operatorname{Max} \mid \mathrm{Fa}(\mathrm{X})-\mathrm{Fe}(\mathrm{X})
$$

Dari Tabel 5, Nilai D maksimum adalah 0,152331 yang berada pada data ke 14 .

Maka:

$\mathrm{D}_{\text {Hit }}>\mathrm{D} \alpha_{(0,05)}(0,294>0,152331)$

Wilayah penerimaan untuk pengambilan keputusannya :

Ho : Data berdistribusi normal

$\mathrm{H}_{\mathrm{i}}$ : Data tidak berdistribusi normal

Jika $\mathrm{D}>\mathrm{D} \alpha$, maka $\mathrm{H}_{\mathrm{o}}$ diterima

Jika $\mathrm{D}<\mathrm{D} \alpha$, maka $\mathrm{H}_{\mathrm{o}}$ ditolak

Dalam pengumpulan data ini, Ho diterima karena $\mathrm{D}_{\text {Hit }}>\mathrm{D} \alpha$. Ini artinya data berdistribusi normal.
Tabel 5.

Selisih Fa (x) dengan Fe (x)

\begin{tabular}{cccccc}
\hline No & Data $(\mathrm{x})$ & $\mathrm{Fa}(\mathrm{x})$ & $\mathrm{Z}$ & $\mathrm{Fe}(\mathrm{x})$ & $\mathrm{D}$ \\
\hline 1 & 79 & 0,05 & $-2,4753$ & 0,00666 & 0,04334 \\
2 & 82 & 0,1 & $-1,078$ & 0,14053 & 0,04053 \\
3 & 84 & 0,15 & $-0,8783$ & 0,18988 & 0,03988 \\
4 & 86 & 0,2 & $-0,6787$ & 0,24866 & 0,04866 \\
5 & 88 & 0,25 & $-0,4791$ & 0,31594 & 0,06594 \\
6 & 91 & 0,3 & $-0,4791$ & 0,31594 & 0,06594 \\
7 & 94 & 0,35 & $-0,4791$ & 0,31594 & 0,03406 \\
8 & 99 & 0,4 & $-0,2795$ & 0,38994 & 0,01006 \\
9 & 99 & 0,45 & $-0,0798$ & 0,46818 & 0,01818 \\
10 & 100 & 0,5 & $-0,0798$ & 0,46818 & 0,03182 \\
11 & 102 & 0,55 & $-0,0798$ & 0,46818 & 0,08182 \\
12 & 102 & 0,6 & 0,11977 & 0,54767 & 0,05233 \\
13 & 107 & 0,65 & 0,11977 & 0,54767 & 0,10233 \\
14 & 109 & 0,7 & 0,11977 & 0,54767 & 0,15233 \\
15 & 110 & 0,75 & 0,51902 & 0,69813 & 0,05187 \\
16 & 110 & 0,8 & 0,51902 & 0,69813 & 0,10187 \\
17 & 114 & 0,85 & 0,91826 & 0,82076 & 0,02924 \\
18 & 116 & 0,9 & 0,91826 & 0,82076 & 0,07924 \\
19 & 116 & 0,95 & 1,71675 & 0,95699 & 0,00699 \\
20 & 119 & 1 & 2,11599 & 0,98283 & 0,01717 \\
\hline
\end{tabular}

\subsection{Perhitungan ANAVA untuk Menguji Hipotesa}

Pengujian analisis variansi dilakukan untuk mengetahui apakah faktor- faktor yang diteliti berpengaruh signifikan terhadap variabel respon tersebut. Faktor yang akan diuji adalah temperatur dan kebisingan.

Hipotesis yang akan diuji adalah :

- H01 : Temperatur tidak berpengaruh secara signifikan terhadap frekuensi denyut jantung operator.

- $\mathrm{H}_{2} 2$ : Kebisingan tidak berpengaruh secara signifikan terhadap frekuensi denyut jantung operator.

- H03: Interaksi temperature dan kebisingan tidak berpengaruh secara signifikan terhadap frekuensi denyut jantung operator.

- H11 : Temperatur berpengaruh secara signifikan terhadap frekuensi denyut jantung operator.

- H12 : Kebisingan berpengaruh secara signifikan terhadap frekuensi denyut jantung operator.

- H13 : Interaksi temperatur dan kebisingan berpengaruh secara signifikan terhadap frekuensi denyut jantung operator.

Adapun hasil perhitungan ANAVA untuk eksperimen faaktorial $2 \times 2$ dapat dilihat pada tabel berikut. 
Tabel 5.

Daftar ANAVA untuk Eksperimen Faktorial 2 x 2

\begin{tabular}{ccccccc}
\hline Source & JK & df & KT & $\begin{array}{c}\mathrm{F} \\
\text { hitung }\end{array}$ & $\begin{array}{c}\mathrm{F} \\
\text { Tabel }\end{array}$ & $\begin{array}{c}\text { Kesim } \\
\text { pulan }\end{array}$ \\
\hline $\begin{array}{c}\text { Rata- } \\
\text { rata } \\
\text { A }\end{array}$ & $201.402,45$ & 1 & & & & \\
B & 8802,05 & 1 & 1602,05 & 144,65 & 3,59 & $\begin{array}{c}\mathrm{H}_{\mathrm{i}} \\
\text { diterima }\end{array}$ \\
AxB & 18,05 & 1 & 18,05 & 1,63 & 3,59 & $\begin{array}{c}\mathrm{H}_{\mathrm{i}} \\
\text { ditolak }\end{array}$ \\
Error & 177,2 & 16 & 11,075 & & & \\
Total & 204.287 & 20 & & & & \\
\hline
\end{tabular}

Adapun penetapan hipotesa yang digunakan adalah sebagai berikut:

Hipotesa Awal $\left(\mathrm{H}_{0}\right) \quad=$ Tidak terdapat efek yang signifikan

Hipotesa Alternatif $\left(\mathrm{H}_{\mathrm{i}}\right)=$ Terdapat efek yang signifikan

Dan syarat untuk melakukan pengujian hipotesa adalah sebagai berikut:

$\mathrm{F}_{\text {hit }} \leq \mathrm{F}_{\text {tabel }}, \mathrm{H}_{\mathrm{o}}$ diterima

$\mathrm{F}_{\text {hit }}>\mathrm{F}_{\text {tabel }}, \mathrm{H}_{\mathrm{o}}$ ditolak

Sehingga dari tabel ANAVA di atas didapat beberapa kesimpulan sebagai berikut:

- $\mathrm{F}_{\mathrm{A}}>\mathrm{F}_{\text {tabel }}, \mathrm{H}_{01}$ ditolak dan $\mathrm{H}_{\mathrm{i} 1}$ diterima, temperatur berpengaruh secara signifikan terhadap frekuensi denyut jantung operator

- $\mathrm{F}_{\mathrm{B}}>\mathrm{F}_{\text {tabel }}, \mathrm{H}_{02}$ ditolak dan $\mathrm{H}_{\mathrm{i} 2}$, Kebisingan berpengaruh secara signifikan terhadap frekuensi denyut jantung operator

- $\mathrm{F}_{\mathrm{AB}}<\mathrm{F}_{\text {tabel }}, \mathrm{H}_{03}$ diterima dan $\mathrm{H}_{\mathrm{i} 3}$ ditolak, Interaksi temperature dan kebisingan tidak berpengaruh secara signifikan terhadap frekuensi denyut jantung operator.

\subsection{Analisis Frekuensi Denyut Jantung Operator}

Variabel respon yang diamati pada penelitian ini adalah besarnya frekuensi denyut jantung operator setelah bekerja selama 4-5 jam. Dari beberapa faktor yang mempengaruhi besarnya frekuensi denyut jantung, faktor temperatur dan kebisingan dijadikan sebagai faktor yang akan diubahubah nilainya. Hal tersebut disebabkan karena kedua faktor tersebut mempunyai nilai pengukuran yang bersifat kuantitatif, mudah diukur dan sesuai dengan kondisi di tempat penelitian.

Untuk faktor temperatur, besarnya frekensi denyut jantung mempunyai nilai rata-rata yang berbeda untuk level A1 (24-28 $\left.{ }^{\mathrm{O}} \mathrm{C}\right)$ dan level A2. Pada temperatur $24-28{ }^{\circ} \mathrm{C}$ besarnya rata-rata frekuensi denyut jantung sebesar 79 denyut per menit, dengan nilai maksimum sebesar 84 denyut per menit dan nilai minimumnya sebesar 69 denyut per menit. Sedangkan pada temperatur $29-34{ }^{\circ} \mathrm{C}$, besarnya rata-rata frekuensi denyut jantung sebesar 83,8 denyut per menit, dengan nilai maksimum sebesar 92 denyut per menit dan nilai minimumnya sebesar 77 denyut per menit. Berdasarkan data dari pengukuran denyut nadi, terdapat perbedaan nilai frekuensi denyut jantung yang signifikan pada level yang berbeda merupakan salah satu bukti sederhana adanya pengaruh temperatur terhadap frekuensi denyut jantung. Semakin tinggi temperatur, maka tubuh akan cenderung untuk mengkonsumsi energi yang lebih besar (Wignjosoebroto, 1995). Besaran denyut jantung merupakan salah satu indikator besarnya konsumsi energi manusia.

Untuk faktor kebisingan, besarnya frekensi denyut jantung mempunyai nilai rata-rata yang berbeda untuk level B1 (80-84 dB) dan level B2 (85-88 dB). Pada tingkat kebisingan 80-84 dB, besarnya rata-rata frekuensi denyut jantung sebesar 78,5 denyut per menit, dengan nilai maksimum sebesar 82 denyut per menit dan nilai minimumnya sebesar 69 denyut per menit. Sedangkan pada tingkat kebisingan $85-88 \mathrm{~dB}$, besarnya rata-rata frekuensi denyut jantung sebesar 84,3 denyut per menit, dengan nilai maksimum sebesar 92 denyut per menit dan nilai minimumnya sebesar 79 denyut per menit. Berdasarkan data dari pengukuran denyut nadi, terdapat perbedaan nilai frekuensi denyut jantung yang signifikan pada level yang berbeda merupakan salah satu bukti sederhana adanya pengaruh kebisingan terhadap frekuensi denyut jantung.

\subsection{Analisis Persentase Kontribusi Faktor}

Presentase kontribusi tiap faktor atau sumber variansi didapatkan dengan membandingkan antara nilai pure sum of square suatu sumber variansi dengan total sum of square-nya. Sumber variansi pada penelitian ini berasal dari faktor temperatur, kebisingan dan interaksi temperatur-kebisingan. Adapun hasil Presentase kontribusi dengan menggunakan software SPSS16,0 adalah sebagai berikut: 
Total Variance Explained

\begin{tabular}{cccr}
\multicolumn{4}{c}{ Total Variance Explained } \\
\hline \multirow{2}{*}{ Component } & \multicolumn{3}{c}{ Initial Eigenvalues } \\
\cline { 2 - 4 } & Total & \% of Variance & Cumulative \% \\
\hline 1 & 1.771 & 59.032 & 59.032 \\
2 & 1.000 & 33.333 & 92.365 \\
3 & .229 & 7.635 & 100.000 \\
\hline \multicolumn{2}{l}{ Extraction Method: Principal Component Analysis. }
\end{tabular}

Gambar 2. Persentase Kontribusi menggunakan SPSS 20

\begin{tabular}{|c|c|c|c|c|}
\hline Model & R & R Square & $\begin{array}{c}\text { Adjusted } \\
\text { R Square }\end{array}$ & $\begin{array}{c}\text { Std. Error of } \\
\text { the Estimate }\end{array}$ \\
\hline 1 & $.771^{2}$ & .594 & .547 & 3.37290 \\
\hline \multicolumn{6}{|c}{ a. Predictors: (Constant), Kebisingan, Temperatur }
\end{tabular}

Gambar 3. Hasil Korelasi Ganda menggunakan SPSS 20

Faktor yang memberikan kontribusi terbesar adalah temperatur sebesar 59,032\%. Sedangkan faktor kebisingan memberikan kontribusi sebesar 33,333\%, dan interaksi kedua faktor tersebut hanya memberikan kontribusi sebesar 7,635 \%. Jika dijumlahkan, besar kontribusi ketiga faktor tersebut sebesar 59,4\% atau sama dengan nilai Adjusted $R$ Squared. Kontribusi kedua faktor tersebut sangat kecil terhadap besarnya frekuensi denyut jantung. Hal tersebut diduga masih terdapat faktor-faktor lain yang ikut berpengaruh terhadap hasil penelitian dan tidak dapat dikendalikan oleh peneliti, namun ikut berkontribusi terhadap frekuensi denyut jantung. Faktor lain tersebut antara lain tingkat emosi, kondisi kesehatan yang tidak diketahui oleh operator itu sendiri, aktivitas kerja yang tidak normal, dan lain-lain.

3.6 Pengaruh Temperatur dan Kebisingan Terhadap Kesehatan Cardiovascular

Hasil uji anova menunjukkan bahwa temperatur dan kebisingan berpengaruh terhadap frekuensi denyut jantung, walaupun diduga terdapat juga faktor-faktor lain yang berpengaruh. Kondisi temperatur dan kebisingan di area produksi khusunya stasiun pengepresan di PT. Canang Indah Medan yang tidak ergonomis menjadi pengaruh besarnya frekuensi denyut jantung yang mencapai 92 denyut per menit dengan nilai rata-rata sampel sebesar 81,4 denyut per menit. Estimasi nilai rata-rata populasi berkisar 76,767 hingga 82,43 . Besarnya frekuensi denyut jantung manusia normal berkisar 60-90 denyut per menit dengan rata-rata sebesar 75 denyut per menit (Ma'sud, 1997). Jika dibandingkan kedua nilai rata-rata tersebut mempunyai perbedaan yang cukup jauh. Hal tersebut diduga disebabkan karena operator produksi telah terkena pengaruh kondisi lingkungan yang tidak ergonomis selama bertahun-tahun. Kondisi tersebut mempunyai efek jangka panjang yang terkait pada gangguan hormonal, seperti keluhan psikosomatik akibat gangguan saraf otonom, serta aktivasi hormon kelenjar adrenal seperti hipertensi, disritmia jantung, dan sebagainya. (Arifiani, 2006).

Besarnya frekuensi denyut jantung yang berada di atas batas normal (takikardia) dapat menyebabkan iskemia. Iskemia mengakibatkan darah tidak mengalir ke seluruh bagian tubuh, sehingga terdapat organ-organ tertentu tidak mendapatkan nutrisi yang cukup. Penurunan aliran darah akibat meningkatnya denyut jantung dapat mengakibatkan kepala pusing, hingga pingsan. Pemaparan lingkungan yang tidak ergonomis secara terus menerus diindikasikan dapat memperparah iskemia, yang merupakan salah satu gejala serangan jantung.

\section{Simpulan}

Berdasarkan hasil pembahasan maka dapat diambil beberapa kesimpulan beberapa berikut :

1. Dari tiga sumber variasi uji anova dihasilkan kesimpulan bahwa hanya dua sumber variasi yang berpengaruh terhadap frekuensi denyut jantung operator produksi yaitu temperatur dan kebisingan. Hal tersebut ditunjukkan dengan nilai $\mathrm{F}$ hitung yang lebih besar daripada nilai $\mathrm{F}$ tabel. Untuk faktor temperatur, $H_{0}$ ditolak karena nilai $F$ hitung $(144,65)$ lebih besar daripada $F$ tabel $(3,59)$ dan untuk faktor kebisingan, $H_{0}$ ditolak karena nilai Fhitung (79,86) lebih besar daripada $F$ tabel (3,59). Sedangkan interaksi kedua faktor tersebut tidak berpengaruh terhadap frekuensi denyut jantung, karena mempunyai nilai $F$ hitung hanya sebesar 1,63 .

2. Berdasarkan perhitungan persentase kontribusi, faktor temperatur berkontribusi sebesar 59,032\% dan faktor kebisingan sebesar 33,333\%. Sedangkan interaksi faktor temperatur dan kebisingan hanya berkontribusi sebesar 7,635 \% . Kecilnya total kontribusi faktor diduga karena terdapat faktor-faktor lain yang ikut mempengaruhi frekuensi denyut jantung namun tidak dapat dikendalikan.

\section{Saran}

Saran-saran yang dapat diberikan dari penelitian ini sebagai berikut: 
1. Pihak perusahaan diharapkan mempunyai kebijakan perlindungan kesehatan tenaga kerja yang berfungsi untuk melindungi tenaga kerja dari kondisi lingkungan kerja yang tidak ergonomis.

2. Sebaiknya pihak manajemen meninjau kembali faktor lingkungan di area produksi untuk kesehatan tenaga kerja guna meningkatkan produktivitas operator.

3. Secara berkala melakukan pengujian faktorfaktor lingkungan apa saja yang dapat mempengaruhi hasil kerja operator sehingga menimkan kecelakaan kerja, penyakit efek kerja sehingga dapat memaksimalkan hasil produksi.

\section{Daftar Pustaka}

Adiputra, I Nyoman. Denyut Jantung dan Kegunaannya dalam Ergonomi. Denpasar : Prosiding Seminar Ergonomi Indonesia, 2002.

Arifiani, Novi. Pengaruh Kebisingan terhadap Kesehatan Tenaga Kerja. Jakarta : Jurnal Kedokteran Okupasi, Fakultas Kedokteran Universitas Indonesia.2006

Arikunto, Suharsimi. Prosedur Penelitian : Suatu Pendekatan Praktek.Jakarta :Penerbit Rineka Cipta, 1998.

Depnakertrans RI. 2011. PER.13/MEN/X/2011 Tentang Nilai Ambang Batas Faktor Fisika dan Faktor Kimia di Tempat Kerja. Depnakertrans RI. Jakarta Indonesia.

Ganong, WF. Review of Medical Physiology. Jakarta : Penerbit Buku Kedokteran EGC. 1997.

Guyton, Arthur. Buku Ajar Fisiologi Kedokteran Edisi 9. Jakarta : Penerbit Buku Kedokteran EGC. 1997.

Ghozali, Imam. Aplikasi Analisis Multivariat dengan Program SPSS. Semarang : Penerbit Universitas Diponegoro, 2000.

Hantoro, Sirod. Analisis Tingkat Kebisingan di Departemen Permesinan dan Fabrikasi Fakultas Teknik Universitas Negeri Yogyakarta. Prosiding Seminar Nasional Perkembangan Sistem Manufaktur Dalam Era Teknologi Informasi, 2002.
Hicks, Charles. Fundamental Concepts in the Design of Experiments. Florida : Saunders College Publishing. 1993

Jatmiko, Brury. Analisis Pengaruh Temperatur, Kebisingan dan Pencahayaan Terhadap Produktivitas Kerja Pengeleman Amplop Secara Manual. Surakarta : Jurusan Teknik Industri UNS. 2005.

Kertohoesodo, Soehardo. Pencegahan Penyakit Jantung. Jakarta : Penerbit Pradnya Paramitha, 1988.

Kertohoesodo, Soehardo. Pengantar Kardiologi. Jakarta : Penerbit Universitas Indonesia, 1987.

Krisiya, Jwalitasari. Analisis Pengaruh Jenis Musik Terhadap Performansi Kerja Operator Input Data. Surakarta : Jurusan Teknik Industri UNS. 2006.

Manuaba, A. 2000. Penerapan Ergonomi Meningkatkan Produktivitas. Makalah. Denpasar: Bagian Ilmu Faal Fakultas Kedokteran Universitas Udayana.

Manuaba, A. 1998. Bunga Rampai Ergonom I. Udayanan University Press : Denpasar.

Wignjosoebroto, S. 2000. Ergonomi, Studi Gerak Dan Waktu Teknik Analisis Untuk Peningkatan Produktivitas Kerja. Surabaya : Guna Widya.

www.wikipedia.com/sistemcardiovascular/jantun g, Desember 2017.

www.itl.nist.gov/div898/handbook/eda/section3/ eda35a.htm, Desember 2017. 